\title{
Blast Parameter Optimization Study Based on a Blast Crater Experiment
}

\author{
Xi-liang Zhang, ${ }^{1,2}$ Hai-bao Yi $\mathbb{D}^{2,3}$ Hong-hao Ma, ${ }^{1,4}$ and Zhao-wu Shen ${ }^{1}$ \\ ${ }^{1}$ CAS Key Laboratory of Mechanical Behavior and Design of Materials, University of Science and Technology of China, \\ Anhui, Hefei 230026, China \\ ${ }^{2}$ Sinosteel Maanshan Institute of Mining Research, Co., Ltd., Anhui, Maanshan 243000, China \\ ${ }^{3}$ State Key Laboratory of Safety and Health for Metal Mines, Anhui, Maanshan 243000, China \\ ${ }^{4}$ State Key Laboratory of Fire Science, University of Science and Technology of China, Anhui, Hefei 230026, China \\ Correspondence should be addressed to Hai-bao Yi; hang_tianfeiji@126.com
}

Received 16 January 2018; Revised 2 April 2018; Accepted 8 May 2018; Published 5 July 2018

Academic Editor: Elena Dragomirescu

Copyright (C) 2018 Xi-liang Zhang et al. This is an open access article distributed under the Creative Commons Attribution License, which permits unrestricted use, distribution, and reproduction in any medium, provided the original work is properly cited.

\begin{abstract}
The blasting quality and the rock volume blasted directly affect the cost of mines. A small charge-forward blast crater experiment was conducted to study the relationships between the rock volume blasted, the explosive unit consumption, the bulk yield, and the depth ratio. The results showed that the rational resistant line or explosive charge depth should be 0.86 times the optimal resistant line. Based on theoretical analysis of the large spacing of the holes and the small resistance line, the uniform design method was used to conduct the lateral blasting crater tests. The relationship equations among the blasting parameters, the blasting volume, and the bulk yield were obtained by regression analysis. The results illustrated that the rock volume blasted was negatively correlated with the bulk yield. The contribution rates of the resistance lines and the spacing of the holes to the blasting volume regression were $32.4 \%$ and $13.9 \%$, respectively, and to the bulk yield regression were $65.0 \%$ and $0.256 \%$. The impact of the resistance line on the blasting volume and the bulk yield was more significant than that of the spacing of the holes. The blasting effect of the rectangular blast hole arrangement was better than that of the square pattern. The blasting technology of large hole spacing and a small resistance line could achieve a better blasting effect while ensuring a higher rock volume blasted. The economical and reasonable blasting parameters were determined as the hole spacing of $\mathrm{a}=8.5 \mathrm{~m}$ and the resistance line width of $\mathrm{W}=5.5 \mathrm{~m}$, with the rock volume blasted of $413.1 \mathrm{~m}^{3}$ and the bulk rate of $0.218 \%$. This method provides an effective method for optimization of the blasting parameters and has important guiding significance for efficient and economical mining.
\end{abstract}

\section{Introduction}

In the mining process, open pits are often faced with the problem of balancing the blasting quality and the volume of rock blasted. If the blasting quality is poor, the large block rate is high, and the block size is not uniform, it will bring difficulty to the loading and crushing work, resulting in an increase in production costs. If the blasting quality is good but the blasting volume is often low, then the overall cost is still relatively high.

Therefore, obtaining a better blasting quality, reducing the bulk rate, reducing the unit consumption of explosives, and controlling the overall cost are the actual technical problems that must be resolved under the condition of ensuring a high blasting volume. The scientific determination of reasonable blasting parameters is the key to obtaining a good blasting effect. In the blasting design, the blasting parameters are generally selected with reference to the similar conditions for the mine; this approach has certain limitations and often has a certain deviation from the actual site. Usually, the blast parameters are not the same, even if the same type of explosive is used, because of the different rock characteristics. It is well-known that Livingstone's blasting crater theory plays an important role in finalizing the blast parameters [1].

Many experts and scholars have conducted many research studies to reduce the blasting cost in the mines; such studies can be categorized into three types. The first type is blasting crater theoretical analysis. Mr. W. L. Fourney conducted 


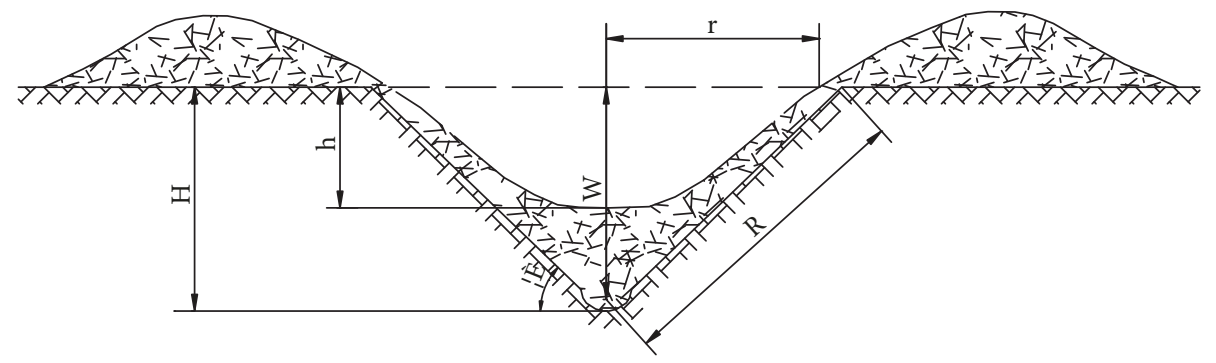

FIGURE 1: Blasting crater schematic. r-Radius of the blasting crater; W-minimum resistant line; R-blasting crater crashed radius; h-visible depth of the blasting crater; $\mathrm{H}$-depth of the blasting crater; $\theta$-crater angle.

a study of the crushing mechanism of the blasting crater. The mechanism of fragmentation was one in which the material between the borehole and the free surface is greatly weakened by the stress waves over the first $50 \mu$ sec or so after detonation. It was proposed that this greatly weakened area is subsequently acted upon by the residual pressure in the hole to create the final crater [2,3]. Mr. Ze Liu's optimization study was conducted using blast parameters of the reduced section tunnel in hard rock based on the blasting mechanism. The optimization of the blasting construction parameters is a dynamic process. The timely adjustments should be made based on the rock conditions to improve the blasting efficiency and reduce the blasting cost [4]. Yixian Wang and his colleagues generated shape-changing energy indices of the rock in coal mines by setting up the formula of the blasting crater parameters based on the theoretical analysis according to the energy balance rule of the Livingstone Blasting Crater. The deformation energy coefficient of hard coal, mid-hard coal, and soft coal was found to be $2 / 62 \mathrm{~m} / \mathrm{kg}^{1 / 3}, 3.05 \mathrm{~m} / \mathrm{kg}^{1 / 3}$, and $3.49 \mathrm{~m} / \mathrm{kg}^{1 / 3}$, respectively [5]. Jin Xu-hao illustrated the important status and function of the blasting crater in the study of the rock blasting mechanism. He noted that the use of the research methods of using fracture mechanics and damage mechanics to establish a blasting failure model and the use of numerical models to calculate and analyze the formation of blasting craters will further deepen the analysis of the mechanism of blasting craters [6]. The second type is the numerical simulation of the blasting crater formation process. Zheming Zhu established the blasting crater value model and analyzed the crushing impact of the stress on both the blasting crater and bench blasting; the study mainly focused on the stress wave loading on rock blasting that had a very important effect on the control and predictions of fragmentation of rock in actual blasting [7]. Mr. P. Yan imitated the dynamic crushing process using a 3DEC model. An equivalent blasting load considering the detonation gas pressure was adopted. The results of the study showed that the muck-pile profile of bench blasting is more sensitive to the burden distance [8]. The third type is the analysis of the rock dynamic fracture process. Y. Zhang studied the dynamic characteristics of thin-layered sandy frozen soil in blasting and discovered that, regardless of the stage of the explosive, there appears a critical point of the changes from tension to compression along the direction from the explosive center to the surroundings within a radius of approximately 0.9 $\mathrm{m}$ [9]. SH Cho and K. Kanekoanalied studied the influence of the applied pressure waveform on the dynamic fracture processes in rock. The study results showed that the fracture processes are affected more by the rise time increases than by the decay time. A higher stress-loading rate increases the number of radial cracks and leads to intense stress release around running cracks. These fracture processes reveal that crack extension increases with the rise time increase [10].

It could achieve a better blasting effect with the method of parameter optimization [11]. The relationships between the rational crushing resistant line and the optimal blasting resistant line were analyzed by the blasting crater experiments. The tests were conducted with the uniform design method. The formulas for the parameters, rock volume blasted, and the blasting quality were obtained by regression analysis. Taking the comprehensive cost into consideration, the rational blasting parameters were decided to provide guidance to achieve efficient mining.

\section{Small Charge-forward Blasting Crater Experiment}

2.1. Experimental Methods. The tests aim to explore the blasting crater parameters and seek the reasonable blasting resistant line to improve the blasting quality, reduce the explosive consumption, and increase the explosive usage efficiency. The experiments were conducted on $\mathrm{a}+24 \mathrm{~m}$ bench in an open pit, where the rock was rich in cracks with the hardness of $\mathrm{f}=12$ to 16 and unit weight of $3.4 \mathrm{t} / \mathrm{m}^{3}$. The diameter of the blasting holes was $250 \mathrm{~mm}$, with the explosive charge of $12 \mathrm{~kg}$ per blast hole. The depth of the explosive was 1.5 to $3.9 \mathrm{~m}$. To eliminate the interaction between the adjacent holes, the distance between two holes that were in the same row was more than $15 \mathrm{~m}$.

The parameters of crater sizes to be measured are the crater radius, the crater volume, and the crater depth; it is commonly accepted that the first two can well reflect the characteristics of a blasting crater. The crater parameters are shown in Figure 1. The explosive locations distribution is shown in Figure 2. Every direction of the radius was measured, as shown in Figure 3; the crater radius $(\mathrm{R})$ is the average of the crater radius in eight different directions with an interval angle of $45^{\circ}$, the center of which is the blast hole. The bulk yield was determined based on the image analysis method. The crater shape can be obtained by averaging the 
TABLE 1: Field experiment results.

\begin{tabular}{|c|c|c|c|c|c|c|c|c|}
\hline No. & $\begin{array}{l}\text { Explosive } \\
\text { depth } \mathrm{L} / \mathrm{m}\end{array}$ & $\begin{array}{l}\text { Depth } \\
\text { ratio } \triangle \\
(\mathrm{L} / \mathrm{Le}) \\
\end{array}$ & $\begin{array}{l}\text { Crater depth } \\
\mathrm{H} / \mathrm{m}\end{array}$ & $\begin{array}{c}\text { Crater radius } \\
\mathrm{R} / \mathrm{m}\end{array}$ & Crater angle & $\begin{array}{c}\text { Crater } \\
\text { volume } \\
\mathrm{V} / \mathrm{m}^{3}\end{array}$ & $\begin{array}{c}\text { Explosive } \\
\text { consumption } \\
\left(\mathrm{kg} / \mathrm{m}^{3}\right)\end{array}$ & Remarks \\
\hline 1 & 1.5 & 0.38 & 1.7 & 2.0 & $99.3^{\circ}$ & 7.12 & 1.69 & \multirow{6}{*}{$\begin{array}{c}\text { Optimal explosive } \\
\text { depth } \mathrm{Lj}\end{array}$} \\
\hline 2 & 1.8 & 0.46 & 2.0 & 2.2 & $95.4^{\circ}$ & 10.14 & 1.19 & \\
\hline 3 & 2.1 & 0.54 & 2.4 & 2.4 & $90.1^{\circ}$ & 14.46 & 0.83 & \\
\hline 4 & 2.5 & 0.64 & 2.2 & 2.0 & $84.5^{\circ}$ & 9.22 & 1.32 & \\
\hline 5 & 2.9 & 0.75 & 1.9 & 1.6 & $80.2^{\circ}$ & 5.09 & 2.38 & \\
\hline 6 & 3.3 & 0.84 & 1.3 & 1.1 & $75.1^{\circ}$ & 1.36 & 9.09 & \\
\hline 7 & 3.9 & 1.00 & & & & & & $\begin{array}{l}\text { Max. explosive } \\
\text { depth Le }\end{array}$ \\
\hline
\end{tabular}

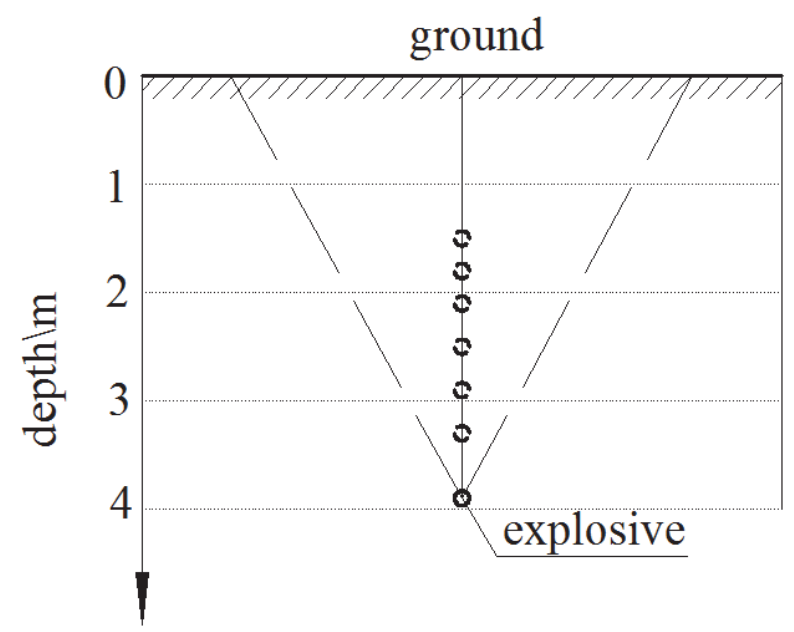

FIGURE 2: Distribution of the locations of the explosives.

heights. The volume of the rock blasted was measured by the Parabolic Method (i.e., the Simpson Method).

2.2. Experiment Results. The explosive depths were chosen from $1.5 \mathrm{~m}$ to $3.9 \mathrm{~m}$. Table 1 shows the results of the experiment.

The relationship between the characteristics of the crater $\mathrm{V} / \mathrm{Q}$ (the crater volume blasted by unit explosive charge) and the depth ratio $\triangle$ is shown in Figure 4 . The relationship curve between the unit explosive consumption $\mathrm{Q} / \mathrm{V}$ and the depth ratio is presented in Figure 5.

The maximum explosive charge depth was $3.9 \mathrm{~m}$. With increasing depth ratio, the crater volume blasted by unit explosive V/Q demonstrated a trend of first increasing and then decreasing. When the explosive depth was at the optimal value of $2.1 \mathrm{~m}$, the value of $\mathrm{V} / \mathrm{Q}$ reached the maximum of $1.21 \mathrm{~m}^{3} / \mathrm{kg}$, with the crater volume blasted of $14.46 \mathrm{~m}^{3}$. With increasing depth ratio $\triangle$, the unit explosive consumption showed a trend of first decreasing and then increasing. V/Q reached the minimum of $0.83 \mathrm{~kg} / \mathrm{m}^{3}$ when the optimal explosive charge depth was $2.1 \mathrm{~m}$. The bulk yield reached the maximum of $0.82 \%$ at the explosive depth of $2.1 \mathrm{~m}$ (or

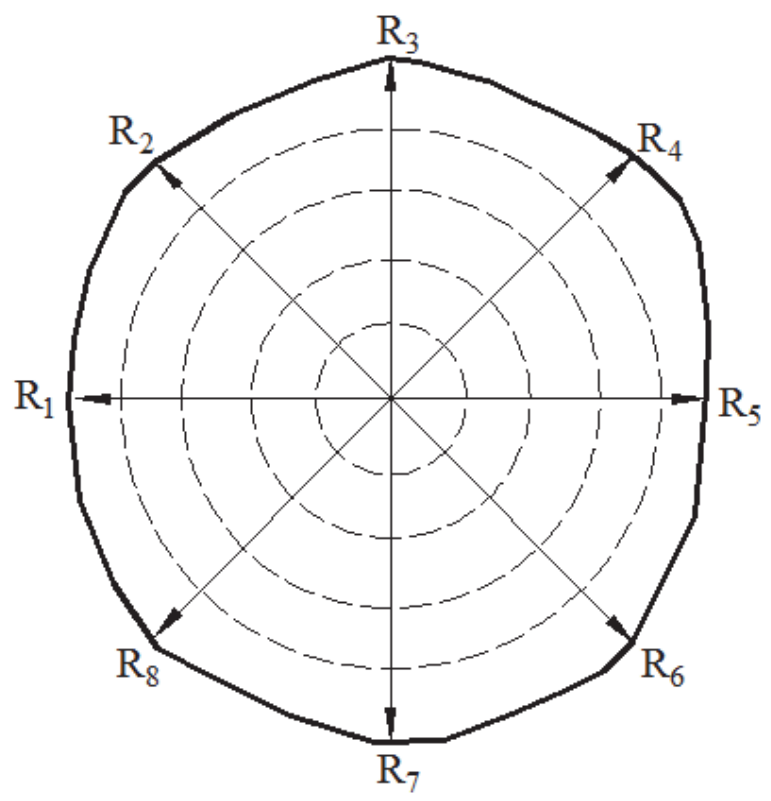

FIGURE 3: Measurement of the crater radius.

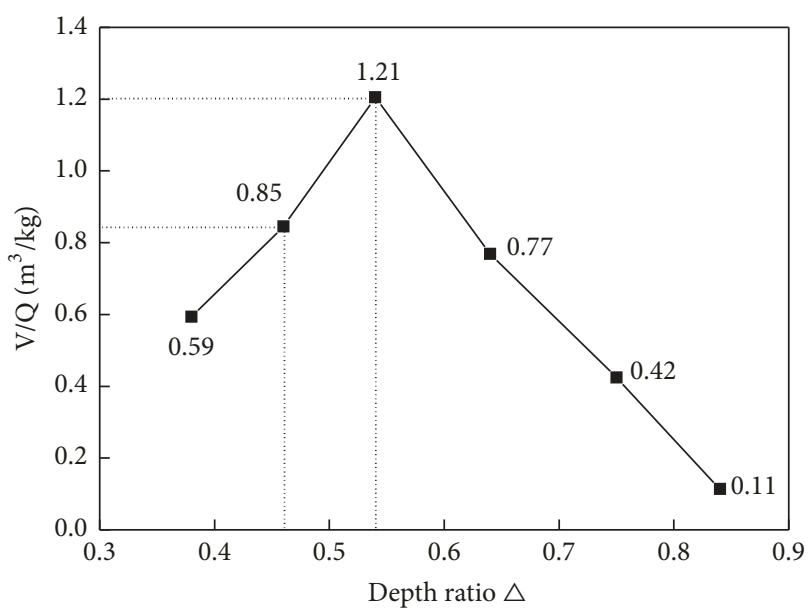

FIgURE 4: Curve of V/Q versus the depth ratio. 


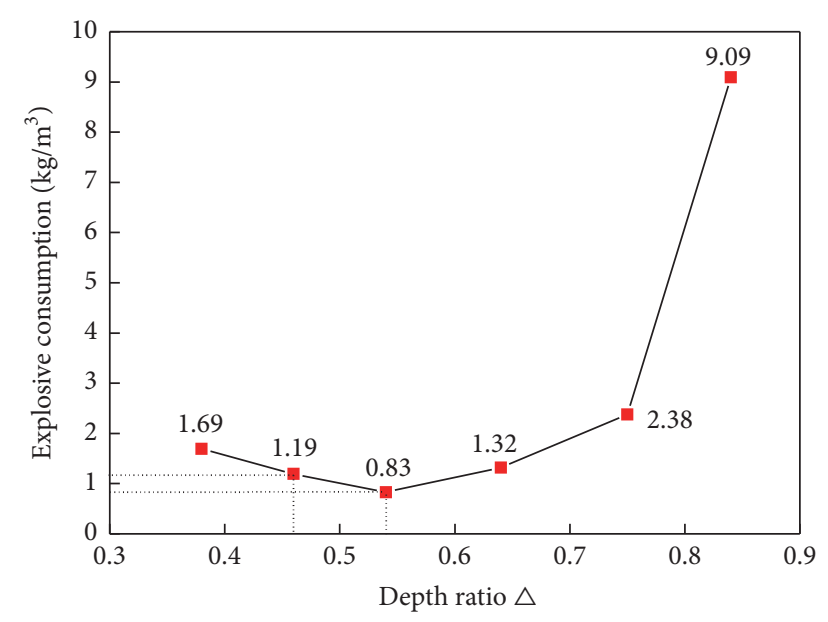

FIGURE 5: Curve of the consumption of explosives versus the depth ratio.

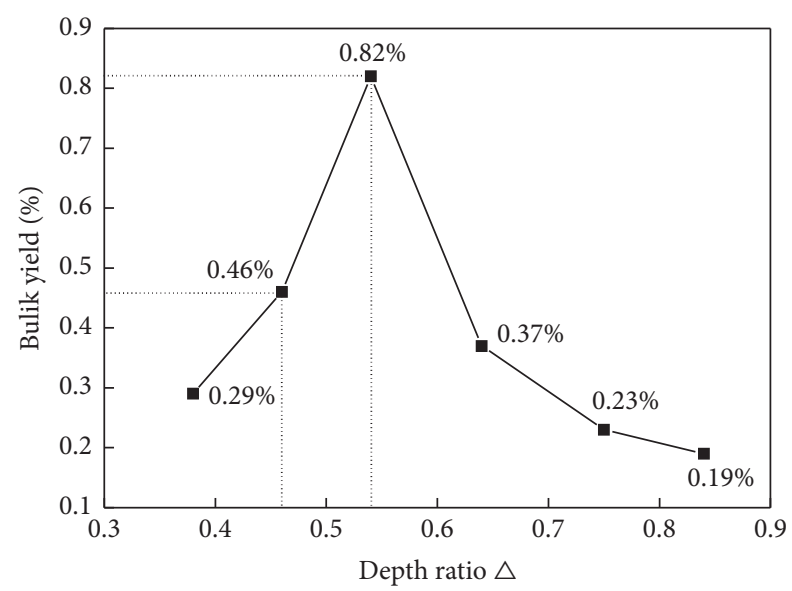

Figure 6: Curve of the bulk yield versus the depth of the explosives.

at the optimal resistant line), as shown in Figure 6. When the explosive depth was $1.8 \mathrm{~m}$, with the depth ratio 0.46 , the unit consumption of explosives reached $1.19 \mathrm{~kg} / \mathrm{m}^{3}$, but the crater volume blasted was high at $10.14 \mathrm{~m}^{3}$. Compared with the depth of $2.1 \mathrm{~m}$, the bulk yield at a depth of $1.8 \mathrm{~m}$ reduced to $0.46 \%$, with the reduction rate of $43.9 \%$. This result illustrated that reducing the explosive depth or decreasing the resistance line properly to $1.8 \mathrm{~m}$ could still achieve a better blast quality. Here, the ratio of $1.8-\mathrm{m} / 2.1-\mathrm{m}$ is 0.86 .

Obviously, the volume of rock blasted and the blast quality are interassociated and mutually conflicting; thus, it is necessary to balance the relationship between them, as mentioned above. From the perspective of the explosive usage efficiency, the explosive energy implied on the rock crushing is a maximum when the crater volume blasted is the maximum with the minimum unit explosive consumption. From the perspective of the mining operation, the blasting quality directly affects the efficiency of the loading, transportation, and crushing, which requires that the bulk yield should be controlled and the rational resistant line must be found.
In summary, the depth ratio must be modestly reduced; i.e., the resistant line should be decreased to guarantee the reasonable resistant line and thus modify the blasting quality in the mining operation. In other words, the optimal blasting quality should be obtained with the premise of achieving a relatively high volume of rock blasted. Based on the analysis above, the reasonable resistant line or the explosive charge depth should be 0.86 times the optimal resistant line, from which the advantage of the reduced resistant line can be enjoyed.

\section{Theoretical Analysis}

3.1. Wave Interference Theory. Research studies have shown that when a few waves propagate in a medium at the same time, whether they meet each other or not, they maintain the original characteristics, including frequency, wavelength, amplitude, and vibration direction. Moreover, they are not affected by other waves. The vibration of any particle in the meeting area is the synthesis of the vibration caused by each wave at this point. This rule is called the wave superposition principle or the independent propagation principle of the wave, as shown in Figure 7.

When two waves of the same frequency are superimposed, the vibrations in some areas are strengthened, the vibrations in some areas are weakened, and the vibrationenhanced area and the vibration-reduced area are separated from each other. This phenomenon is called wave interference [12-14]. When both wave peaks and (or) both wave troughs of the two waves meet, the vibration is strengthened and the vibrations at the peaks and troughs are reduced. If the distance between a certain point to the two wave sources is an integral multiple of the wavelength, then the vibration of the point is strengthened; if the difference is an odd multiple of the half wavelength, then the vibration is weakened (see Figure 8).

Assuming the two wave sources are both simple harmonic vibration, they can be described as follows:

$$
\begin{aligned}
& y_{1}=A_{1} \cos \left(\omega t+\varphi_{1}\right) \\
& y_{2}=A_{2} \cos \left(\omega t+\varphi_{2}\right)
\end{aligned}
$$

where A1, A2 are amplitude, $\omega$ is angular frequency, and $\varphi_{1}$, $\varphi_{2}$ are initial phase.

If the one wave travels along $r_{1}$ and the other travels along $r_{2}$, meeting at a point $P$ in the same medium (see Figure 9), then the partial vibrations caused by these two waves at point $\mathrm{P}$ are

$$
\begin{aligned}
& y_{1}=A_{1} \cos \left(\omega t+\varphi_{1}-\frac{2 \pi r_{1}}{\lambda}\right) \\
& y_{2}=A_{2} \cos \left(\omega t+\varphi_{2}-\frac{2 \pi r_{2}}{\lambda}\right)
\end{aligned}
$$

According to the principle of wave superposition, the combined vibration at point $\mathrm{P}$ is the synthesis of these 


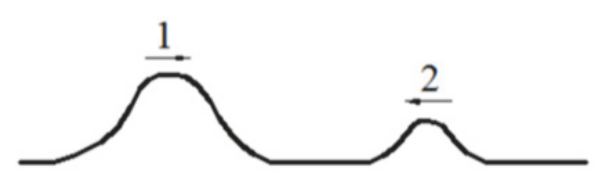

(a)

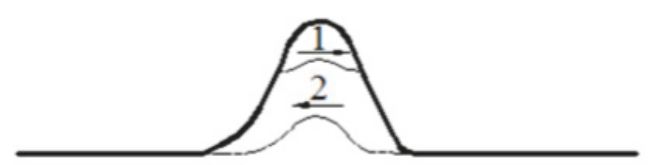

(c)

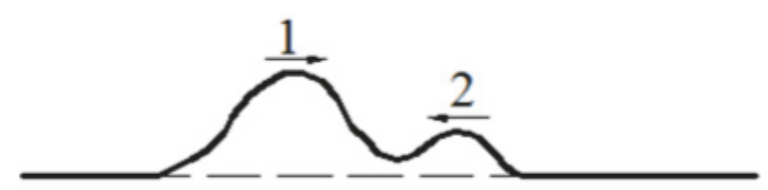

(b)

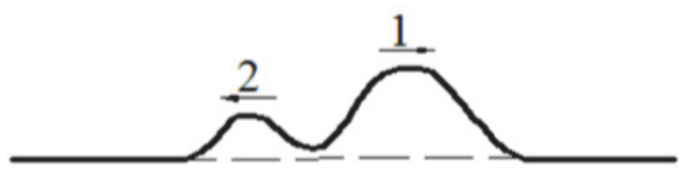

(d)

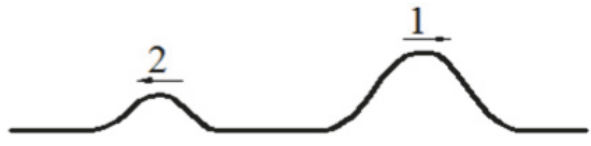

(e)

FIGURE 7: Wave superposition principle.

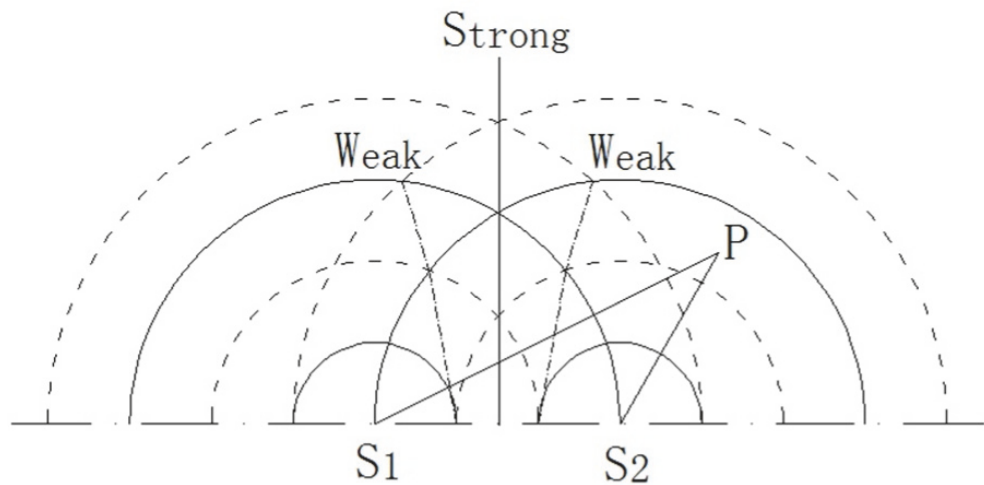

FIGURE 8: Wave interference.

two partial vibrations. The combined vibration equation is expressed as

$$
\begin{aligned}
y= & y_{1}+y_{2} \\
= & A_{1} \cos \left(\omega t+\phi_{1}-\frac{2 \pi r_{1}}{\lambda}\right) \\
& +A_{2} \cos \left(\omega t+\phi_{2}-\frac{2 \pi r_{2}}{\lambda}\right)
\end{aligned}
$$

where $\lambda$ is wavelength.

The combined vibration is still simple harmonic vibration given by

$$
y=A \cos (\omega t+\phi)
$$

where $A$ is amplitude of the combined vibration and $\phi$ is initial phase of the combined vibration.
Thus, we have

$$
\begin{aligned}
& A=\sqrt{A_{1}^{2}+A_{2}^{2}+2 A_{1} A_{2} \cos \left(\phi_{2}-\phi_{1}-2 \pi \frac{r_{2}-r_{1}}{\lambda}\right)} \\
& \phi \\
& =\arctan \frac{A_{1} \sin \left(\phi_{1}-2 \pi r_{1} / \lambda\right)+A_{2} \sin \left(\phi_{2}-2 \pi r_{2} / \lambda\right)}{A_{1} \cos \left(\phi_{1}-2 \pi r_{1} / \lambda\right)+A_{2} \cos \left(\phi_{2}-2 \pi r_{2} / \lambda\right)}
\end{aligned}
$$

If $\phi_{1}=\phi_{2}$, then set $\Delta s=r_{2}-r_{1}$ to express the wavelength difference arriving at point $P$ from the two wave sources.

When $\Delta s=r_{2}-r_{1}=k \lambda, k=0, \pm 1, \pm 2 \ldots, A$ reaches the maximum value, $\mathrm{A}=\mathrm{A}_{1}+A_{2}$.

When $\Delta \mathrm{s}=r_{2}-r_{1}=(2 k+1)(\lambda / 2), k=0, \pm 1, \pm 2 \ldots, A$ reaches the minimum value, $\mathrm{A}=\left|\mathrm{A}_{1}-A_{2}\right|$.

3.2. Mechanism of the Large Spacing of Holes and Small Resistant Line. The blasting technology of large hole spacing a and small resistant line width $W$ is to enhance the distance 


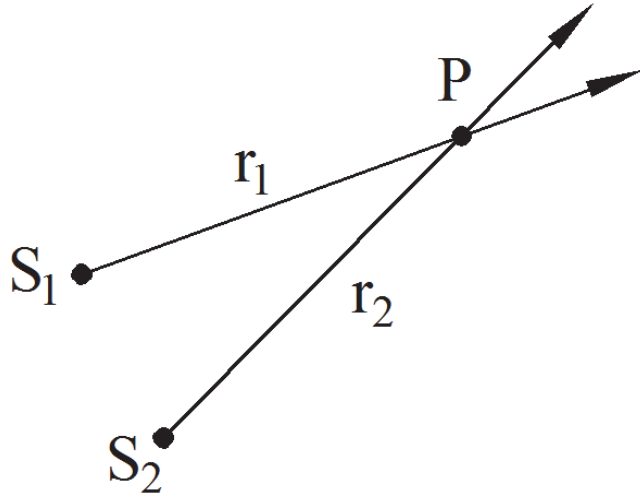

FIgURE 9: Two waves meet at point $\mathrm{P}$.

between two blasting holes that are within the same row and to reduce the distance between two rows under the premise of keeping the square blasted by each hole constant or slightly increased to increase the coefficient of $a / W$. As shown in Figure 10, with the decrease of resistant line $W$ and increase of hole spacing $a$, the two separated blasting craters will be connected.

It has been proved that this technology is effective in improving the blasting effect, reducing the unit consumption of explosives, increasing the amount of detonation, and reducing the blasting cost, as has been well recognized by experts both at home and abroad.

The blasting mechanism is as follows.

(1) The reduction of the resistant line and widening of the blasting crater angle with the blasting impact index of $\mathrm{n}>1$ lead to the generation of an arc surface, which creates a favorable crushing condition.

(2) The enhanced hole spacing eliminates the stress wave interaction between adjacent holes and avoids the early emission of the blasting gas, thereby prolonging the blasting impact duration and improving the usage of the blasting energy.

(3) The increase of hole spacing makes the stress reduction area caused by the interaction between the peak and trough of the blasting holes' radiant wave move out of the blasting impact area. This approach accomplishes the following: makes full use of the role of explosion stress, increases the uniformity of the block, reduces the bulk rate, and improves the blasting crushing quality.

\section{On-Site Lateral Blasting Crater Experiment}

4.1. Uniform Design Method. Uniform design is also called Uniform Design Experimentation. Uniform design was jointly proposed by Professors Fang Kaitai and Wang Yuan of the Applied Mathematics Institute of the Chinese Academy of Sciences in 1978. Uniform design is an application of the "pseudo-Monte Carlo method" in number theory.

Uniform design is implemented through a set of welldesigned tables and only considers the test points evenly distributed within the test range. The experimental points
TABLE 2: Evenly designed $\mathrm{U}_{5}\left(5^{2}\right)$ experiment schedule.

\begin{tabular}{lcc}
\hline No. & Holes spacing/m & Resistant line $/ \mathrm{m}$ \\
\hline 1 & 6 & 5.5 \\
2 & 7 & 6.5 \\
3 & 8 & 5 \\
4 & 9 & 6 \\
5 & 10 & 7 \\
\hline
\end{tabular}

are well balanced and dispersed within the scope of the test, but they still reflect the main characteristics of the system. Uniform design can greatly reduce the number of experiments and can achieve the test results by performing at least one test of orthogonal design.

Because the test results do not have the orderly comparability of the orthogonal test results, the regression analysis method is used for the processing of the test results. Using the model derived from regression analysis, the importance of influencing factors can be analyzed. Moreover, the new conditional tests can be estimated, predicted, and optimized. At present, this method has gained international recognition and has been widely used in fields such as aerospace, chemical engineering, pharmaceuticals, materials, automobiles, and the environment at home and abroad [15-20].

4.2. Experiment Method. To ensure the high volume of rock blasted with favorable blasting quality, the density of blasting holes must be considered to obtain the optimal combination of hole spacing and the resistant line. The experiments were conducted in the Heshangqiao open pit of Nanshan Mining Company, where the rock hardness is $\mathrm{f}=8$ to 12 and the rock has good integrity. The diameter of the holes was $200 \mathrm{~mm}$, with the depth of $12.5 \mathrm{~m}$ and explosive charge of $180 \mathrm{~kg}$ per hole. The rock emulsion explosives used were produced by Maanshan Jiangnan Chemical Co., Ltd. The explosive diameter was $170 \mathrm{~mm}$, with a density of $1.10 \mathrm{~g} / \mathrm{cm}^{3} \sim 1.35$ $\mathrm{g} / \mathrm{cm}^{3}$. The detonation speed was $\geq 3200 \mathrm{~m} / \mathrm{s}$.

To reduce the number of experiments performed and reduce the effect on mine production, the uniform design method was implemented. Two holes were initiated simultaneously in each experiment. The program of two factors and five levels was chosen. The two factors were the hole spacing and the resistant line width. The hole spacing was from $6 \mathrm{~m}$ to $10 \mathrm{~m}$, and the resistant line width was from $5 \mathrm{~m}$ to $7 \mathrm{~m}$. A total of five tests were conducted. Based on the application table of uniform design, the $\mathrm{U}_{5}\left(5^{2}\right)$ test schedule was produced, as shown in Table 2. The blast hole layout is presented in Figure 11 .

A picture of the field experiment is shown in Figure 12, and the blasting crushing effect is shown in Figure 13.

4.3. Analysis of the Experimental Results. The experimental results are presented in Table 3 . The measurement method of the crater parameters was the same as that of the small chargeforward blasting crater experiments.

The choice of regression equation has an important influence on the research results. Through comparative analysis 


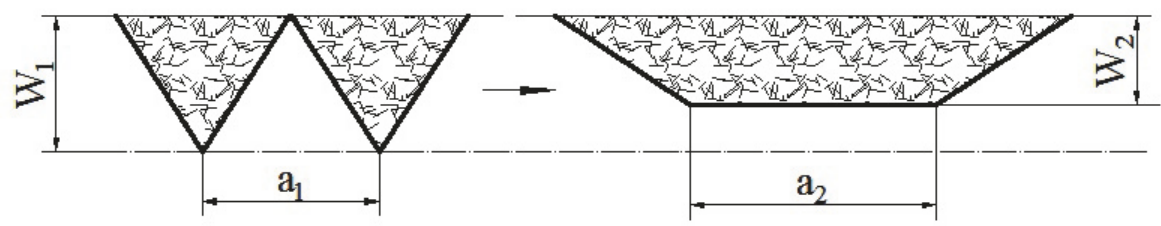

FIGURE 10: Mechanism of the large hole spacing with a small resistant line $\left(\mathrm{a}_{2}>\mathrm{a}_{1} ; \mathrm{W}_{2}<\mathrm{W}_{1}\right)$.

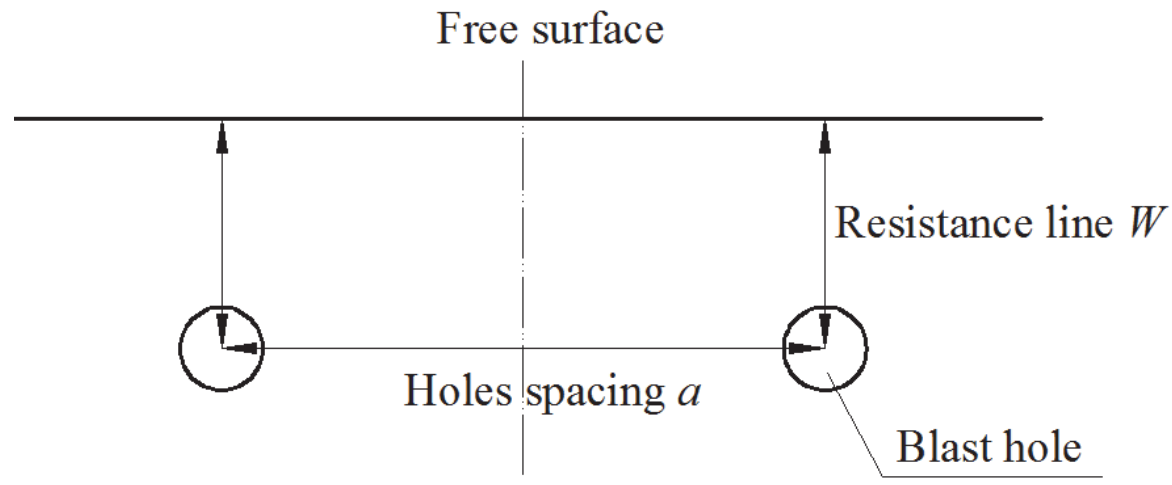

FIGURE 11: Blast hole layout.

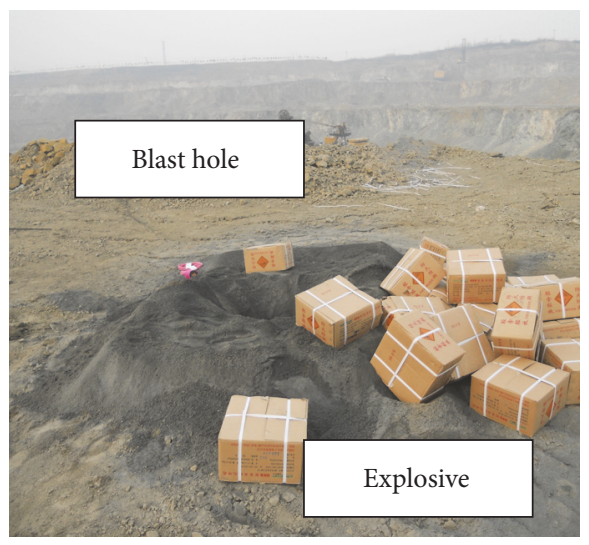

FIgURE 12: Picture of the field experiment.

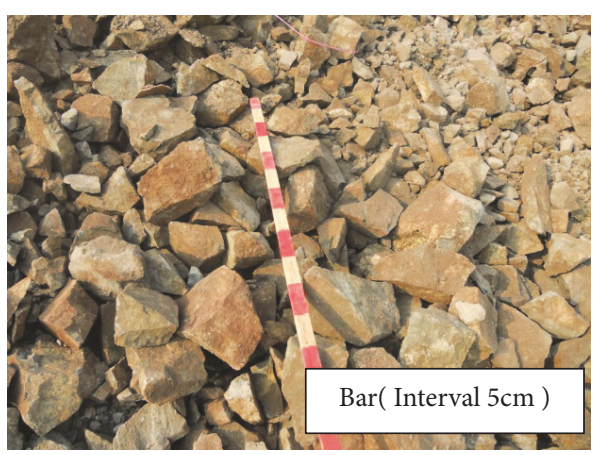

FIGURE 13: Blasting effect. of each built-in equation, the equation with the highest coefficient of determination, $\mathrm{R}^{2}$, is chosen as the objective equation of this paper under the condition that the regression equation is significant.

(1) The regression equation to be established was

$$
\mathrm{y}=\mathrm{b}(0)+\mathrm{b}(1) * x(1) \wedge 2+\mathrm{b}(2) * x(2) \wedge 2
$$

Through the multiple factors regression analysis of the experiment results, regression coefficients b(i) were

$$
\begin{aligned}
& \mathrm{b}(0)=-43.6 ; \\
& \mathrm{b}(1)=2.34 ; \\
& \mathrm{b}(2)=9.51 .
\end{aligned}
$$

Thus, the regression equation for the rock volume blasted was obtained.

$$
y=-43.6+2.34 x_{1}^{2}+9.51 x_{2}^{2}
$$

where $y$ is rock volume blasted, $\mathrm{m}^{3} ; x_{1}$ is hole spacing, $\mathrm{m}$; and $x_{2}$ is resistant line, $\mathrm{m}$.

The regression analysis coefficients are shown in Table 4 and Figure 14.

The regression formula produced the following significant results: sample $\mathrm{N}=5$, significance level $\alpha=0.05$; test value $\mathrm{F}_{\mathrm{t}}=82.87$; critical value $\mathrm{F}(0.05,2,2)=19.00$; and $\mathrm{F}_{\mathrm{t}}>\mathrm{F}(0.05,2,2)$. The regression equation was significant.

Sorted by the partial regression quadratic sum, the contributions of the resistant line and the hole spacing were $32.4 \%$ 
TABLE 3: Experiment results.

\begin{tabular}{|c|c|c|c|c|c|c|}
\hline No. & $\begin{array}{c}\text { Holes spacing } \\
a / \mathrm{m}\end{array}$ & $\begin{array}{c}\text { Resistant line } \\
\qquad / \mathrm{m}\end{array}$ & $\begin{array}{l}\text { Rock volume } \\
\text { blasted } \mathrm{Q} / \mathrm{m}^{3}\end{array}$ & Crater angle & $\begin{array}{c}\text { Explosive } \\
\text { consumption } \\
\left(\mathrm{kg} / \mathrm{m}^{3}\right)\end{array}$ & $\begin{array}{c}\text { Bulk } \\
\text { Yield/\% }\end{array}$ \\
\hline 1 & 6 & 5.5 & 338.3 & $98^{\circ}$ & 0.532 & 0.21 \\
\hline 2 & 7 & 6.5 & 463.6 & $106^{\circ}$ & 0.390 & 0.33 \\
\hline 3 & 8 & 5 & 350.4 & $104^{\circ}$ & 0.519 & 0.18 \\
\hline 4 & 9 & 6 & 467.1 & $113^{\circ}$ & 0.392 & 0.25 \\
\hline 5 & 10 & 7 & 670.0 & $115^{\circ}$ & 0.275 & 0.42 \\
\hline
\end{tabular}

TABLE 4: Regression analysis coefficient.

\begin{tabular}{lcc}
\hline Name & 1 & 2 \\
\hline Regression coefficient b(i) & $\mathrm{b}(1)=2.34$ & $\mathrm{~b}(2)=9.51$ \\
Standard regression coefficient $\mathrm{B}(\mathrm{i})$ & $\mathrm{B}(1)=0.444$ & $\mathrm{~B}(2)=0.678$ \\
Partial regression square sum $\mathrm{U}(\mathrm{i})$ & $\mathrm{U}(1)=9.79 \mathrm{e}^{+3}$ & $\mathrm{U}(2)=2.28 \mathrm{e}^{+4}$ \\
Partial correlation coefficient $\rho(\mathrm{i})$ & $\rho(1,2)=0.9593$ & $\rho(2,1)=0.9819$ \\
Multiple correlation coefficient & $\mathrm{R}=0.9940$ & $\mathrm{R}^{2}=0.9881$ \\
Regression square sum: & $\mathrm{U}=7.03 \mathrm{e}^{+4}$ & \\
\hline
\end{tabular}

TABLE 5: Regression analysis coefficient.

\begin{tabular}{lcc}
\hline Name & 1 & 2 \\
\hline Regression coefficient b(i) & $\mathrm{b}(1)=2.29 \mathrm{e}^{-4}$ & $\mathrm{~b}(2)=9.75 \mathrm{e}^{-3}$ \\
Standard regression coefficient B(i) & $\mathrm{B}(1)=5.98 \mathrm{e}^{-2}$ & $\mathrm{~B}(2)=0.952$ \\
Partial regression square sum $\mathrm{U}(\mathrm{i})$ & $\mathrm{U}(1)=9.44 \mathrm{e}^{-5}$ & $\mathrm{U}(2)=2.39 \mathrm{e}^{-2}$ \\
Partial correlation coefficient $\rho(\mathrm{i})$ & $\rho(1,2)=0.2847$ & $\rho(2,1)=0.9783$ \\
Multiple correlation coefficient & $\mathrm{R}=0.9858$ & $\mathrm{R}^{2}=0.9717$ \\
Regression square sum: & $\mathrm{U}=3.68 \mathrm{e}^{-2}$ & \\
\hline
\end{tabular}

$(\mathrm{U}(2) / \mathrm{U})$ and $13.9 \%(\mathrm{U}(1) / \mathrm{U})$, respectively. The resistant line's contribution was larger than that of hole spacing, demonstrating that the resistant line had a greater impact on the volume of rock blasted.

(2) Based on the regression analysis of multiple factors, the regression equation to be established was

$$
\mathrm{y}=\mathrm{b}(0)+\mathrm{b}(1) * x(1) \wedge 2+\mathrm{b}(2) * x(2) \wedge 2
$$

The regression coefficient $b(i)$ was

$$
\begin{aligned}
& \mathrm{b}(0)=-9.30 \mathrm{e}^{-2} \\
& \mathrm{~b}(1)=2.29 \mathrm{e}^{-4} \\
& \mathrm{~b}(2)=9.75 \mathrm{e}^{-3}
\end{aligned}
$$

The bulk yield formula was the following:

$$
y=-9.3 \times 10^{-2}+2.29 \times 10^{-4} x_{1}{ }^{2}+9.75 \times 10^{-3} x_{2}{ }^{2}
$$

where $y$ is rock volume blasted, $\mathrm{m}^{3} ; x_{1}$ is hole spacing, $\mathrm{m}$; $x_{2}$ is resistant line, $\mathrm{m}$.

The regression analysis coefficients are shown in Table 5 and Figure 15.

The regression formula produced the following significant results: sample content $\mathrm{N}=5$; significance level $\alpha=0.05$; test value $\mathrm{F}_{\mathrm{t}}=34.39$; critical value $\mathrm{F}(0.05,2,2)=19.00$; and $F_{t}>F(0.05,2,2)$. This result showed that the regression formula is significant.

The contributions of the resistant line and the hole spacing (sorted by the partial regression quadratic sum) were $65.0 \%$ and $0.256 \%$, respectively. The resistant line's contribution was greater than that of the hole spacing, demonstrating that the resistant line had a greater impact on the bulk yield. The reduction of the resistant line and increase of the hole spacing are beneficial to controlling the bulk yield.

Considering that the resistant line has a greater impact on the volume of rock blasted and the bulk yield than the hole spacing, reasonably reducing the resistant line and increasing the hole spacing at the same time can obtain favorable blasting quality with a high volume of rock blasted. Thus, the technology of large hole spacing and a small resistant line is reasonable and practical.

4.4. Determination of the Blasting Parameters. The objective function of total mining cost is

$$
\mathrm{C}=\mathrm{C}_{1}+\mathrm{C}_{2}+\mathrm{C}_{3}+\mathrm{C}_{4}+\mathrm{C}_{5}
$$

where $C_{1}$ is drilling cost, $C_{2}$ is blast cost, $C_{3}$ is shovel and loading, $\mathrm{C}_{4}$ is transport cost, and $\mathrm{C}_{5}$ is crushing cost. 

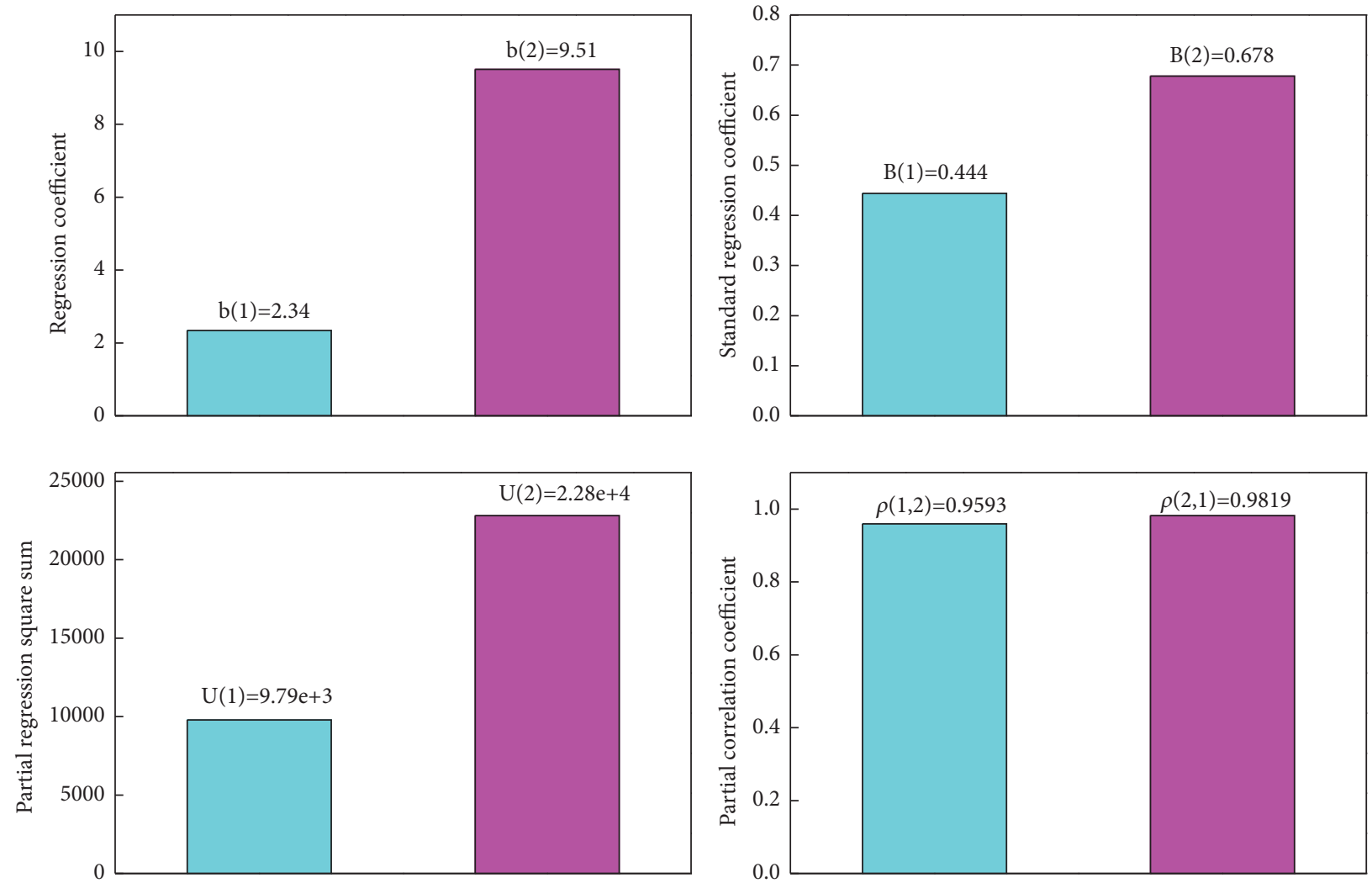

FIGURE 14: Regression analysis coefficient of equation (11).
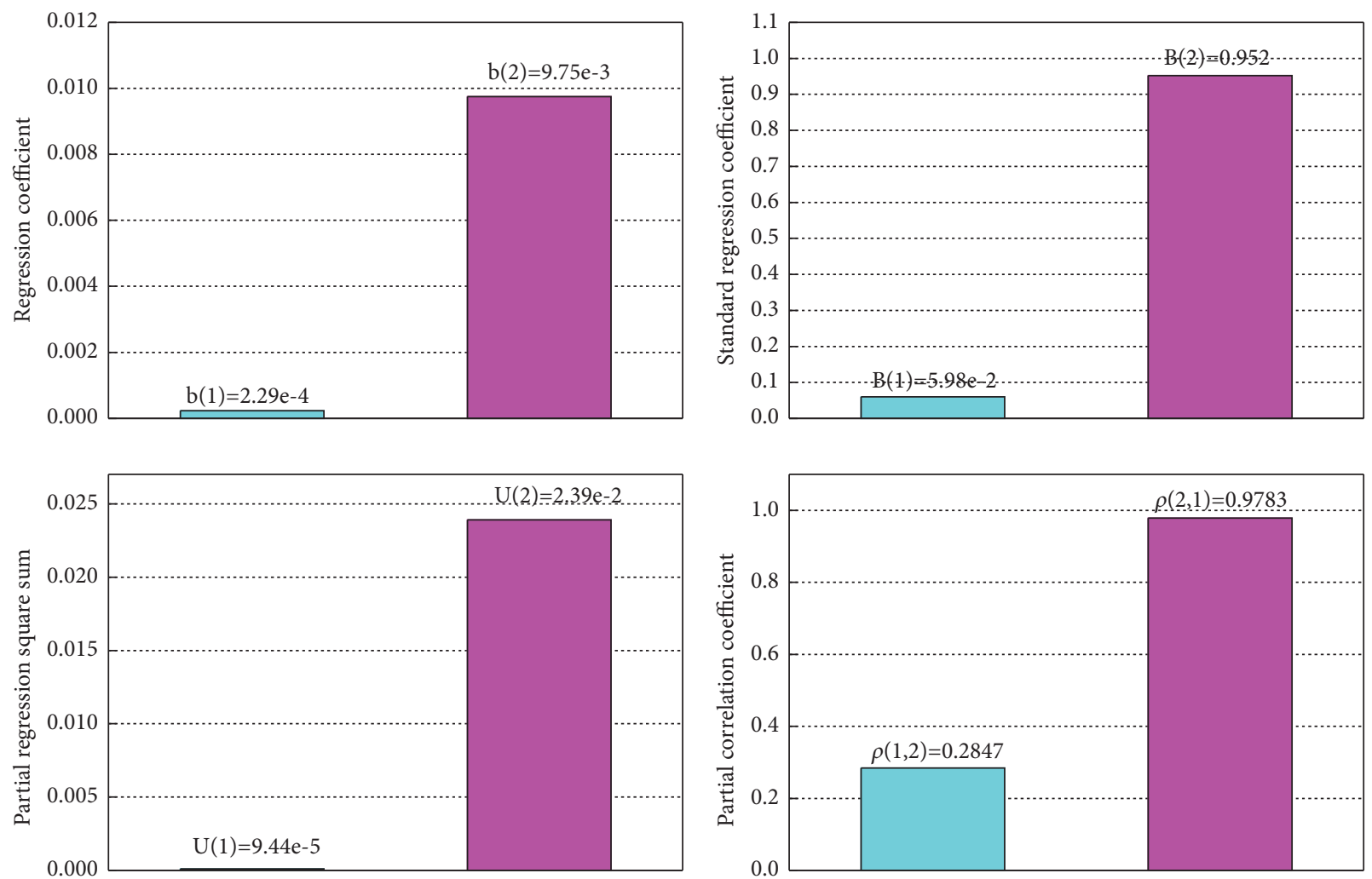

FIgURE 15: Regression analysis coefficient of equation (14). 


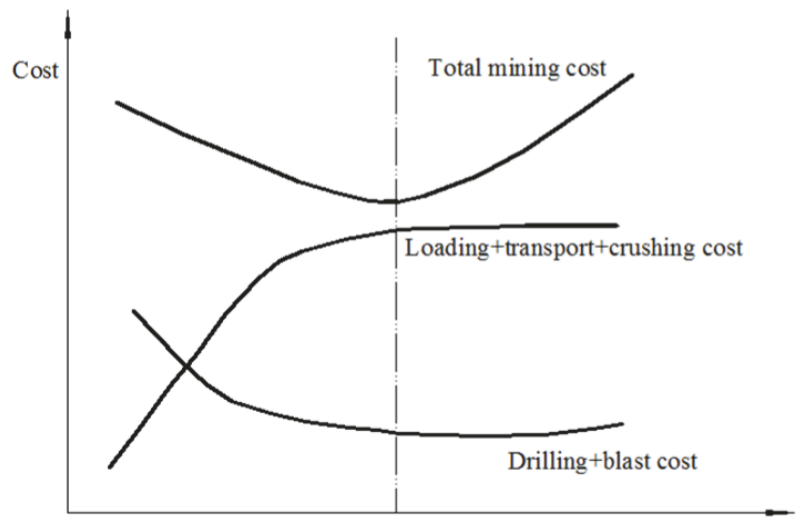

Good $\rightarrow \quad$ Blasting quality $\longrightarrow$ Bad

Figure 16: Blasting quality and mining cost.

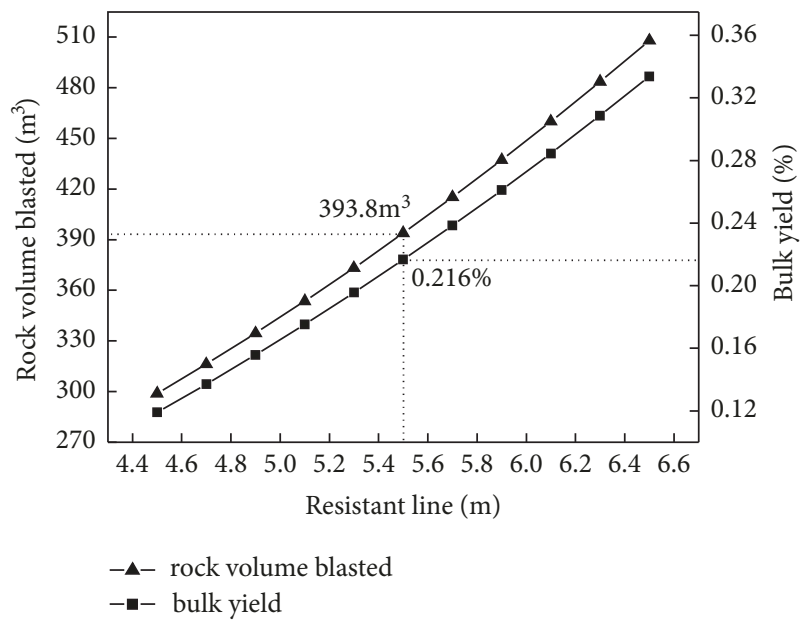

Figure 17: Curves of the resistance line, blasting volume, and bulk yield (hole spacing $a=8 \mathrm{~m}$ ).

The blasting effect not only reflects the accuracy and rationality of the blasting design parameters and the blasting methods but also directly affects the subsequent processes, such as shoveling and loading, transportation and crushing, and the total mining cost.

In general, the costs of drilling and blasting increase with the decrease of blasting quality, and the operating costs of subsequent processes decrease with the improvement of blasting quality. In theory, there is an "optimum blasting effect" that makes the total mining cost the lowest (see Figure 16). On the basis of blasting parameter optimization, the purpose of controlling the comprehensive mining cost can be achieved.

By comparing Figures 17 and 18, under similar hole spacing conditions and with the increase of the resistance line, the amounts of blasting volume and bulk yield both increase. To obtain a larger volume of rock blasted, it is appropriate to increase the resistance line. However, to achieve a better blasting effect and reduce the bulk yield, the resistance line should be reduced properly.

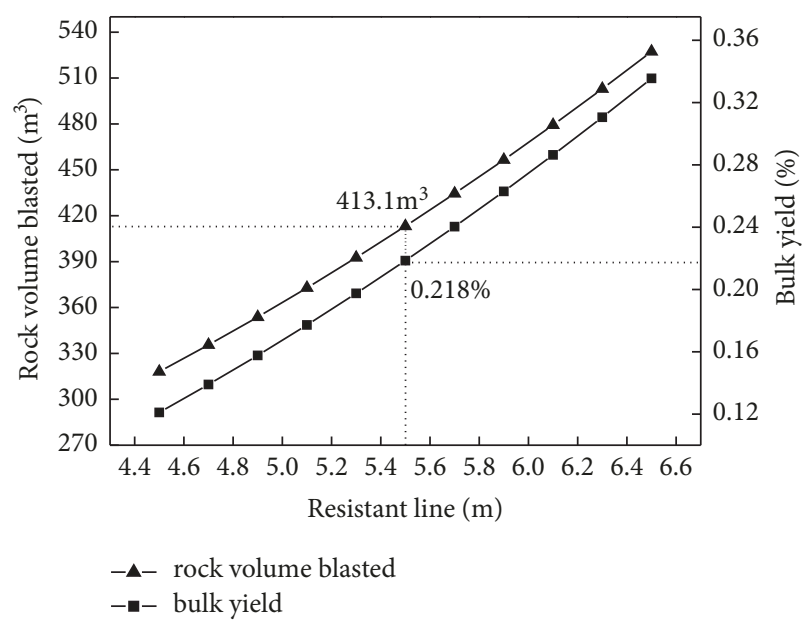

FIGURE 18: Curves of the resistance line, blasting volume, and bulk yield (hole spacing $a=8.5 \mathrm{~m}$ ).

Moreover, if the resistance line is too large, it is difficult to blast the rock, making it not conducive to the formation of a good free surface. Therefore, under the premise of ensuring a higher blasting volume, while the blasting effect is improved, the blasting method of large hole spacing and a small resistance line is suitable.

According to many years of production practice of the Heshangqiao iron mine, comprehensively taking the efficiency of loading/crushing and the total mining cost into consideration, the reasonable and economical blasting parameters are as follows: the hole spacing $a=8.5 \mathrm{~m}$ and resistant line (distance between rows) $W=5.5 \mathrm{~m}$, with the ratio $a / \mathrm{W}=1.55$.

Figures 17 and 18 show that, under the condition that the bulk rate remains basically unchanged, when the resistance line is $5.5 \mathrm{~m}$, the rock volume blasted of $a=8.5 \mathrm{~m}$ can be increased from $393.8 \mathrm{~m}^{3}$ of $a=8 \mathrm{~m}$ to $413.1 \mathrm{~m}^{3}$, representing a $4.9 \%$ increase, thus better illustrating the superiority of the determined blasting parameters.

4.5. Blasting Quality under the Same Blast Area. Figure 19 further verifies the relationships among hole spacing, the volume of rock blasted and bulk yield, in the case of equal blasting area $a \times W=46.75 \mathrm{~m}^{2}(8.5 \mathrm{~m} \times 5.5 \mathrm{~m})$. In the same blasting area of $46.75 \mathrm{~m}^{2}$, with the increase of hole spacing, the resistance line decreases correspondingly. Moreover, the rock volume blasted and bulk yield simultaneously shows a decreasing trend. The negative correlation between blasting volume and bulk yield can be obtained. Thus, it is necessary to comprehensively balance the two relationships above to make the best economic benefits for mining production.

4.6. Blasting Quality Comparison with Perfectly Square Patterns. The blasting quality and volume of six perfectly square patterns were compared, as shown in Table 6 and Figure 20. Here, the hole spacing was equal to the resistance line, $a=\mathrm{W}$. As the hole spacing and the resistance line increase, the blasting volume and the bulk yield increase synchronously. 
TABLE 6: The blasting quality of six perfectly square patterns.

\begin{tabular}{lccccc}
\hline Number & Holes spacing/m & Resistance line $/ \mathrm{m}$ & Blasting area $/ \mathrm{m}^{2}$ & Rock volume blasted $/ \mathrm{m}^{3}$ & Bulk yield $/ \%$ \\
\hline 1 & 4 & 4 & 16 & 146.0 & 0.067 \\
2 & 5 & 5 & 25 & 252.7 & 0.156 \\
3 & 6 & 6 & 36 & 383.0 & 0.266 \\
4 & 6.837 & 6.837 & 46.75 & 510.3 & 0.373 \\
5 & 7 & 7 & 49 & 537.1 & 0.396 \\
6 & 8 & 8 & 64 & 714.8 & 0.546 \\
\hline
\end{tabular}

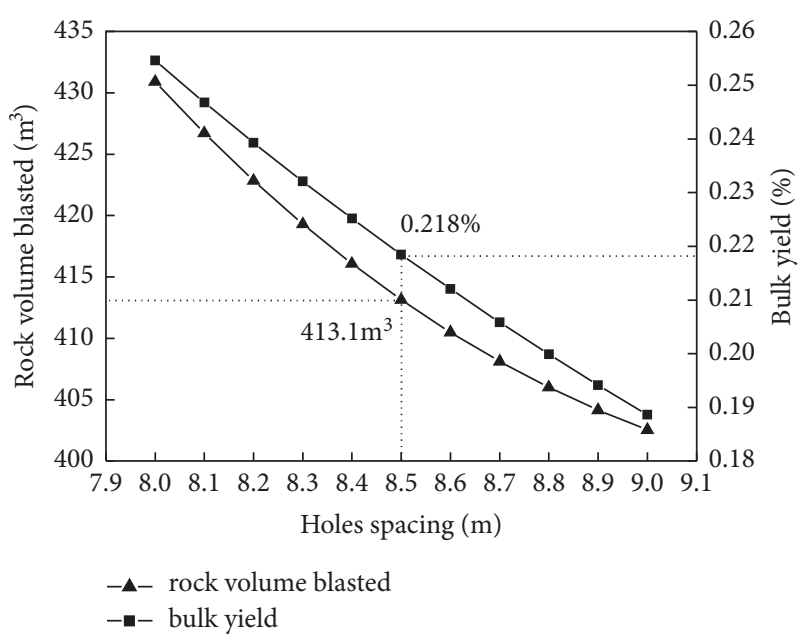

FIgURE 19: Curve of the same blasting area of $46.75 \mathrm{~m}^{2}$.

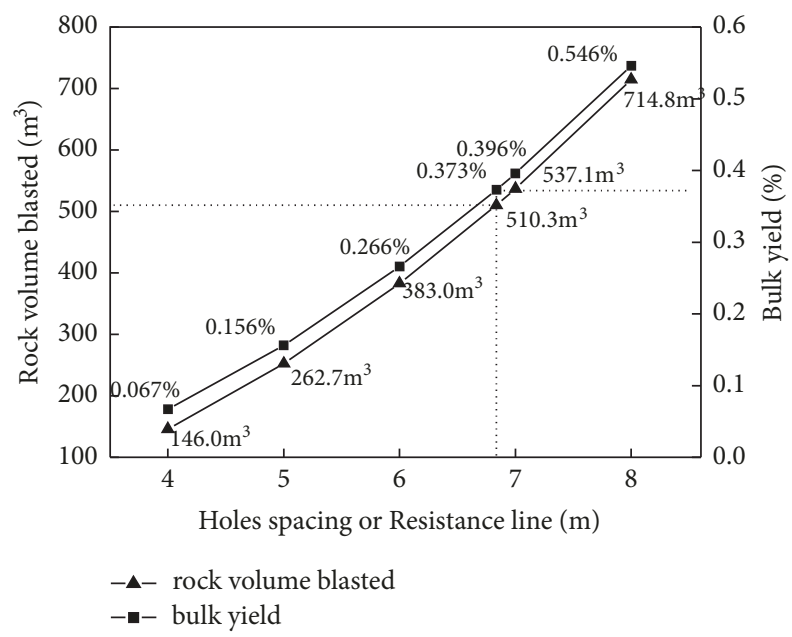

FIGURE 20: The blasting quality of square patterns.

For the perfect square $a \times W=6.837 \mathrm{~m} \times 6.837 \mathrm{~m}$ (area of $46.75 \mathrm{~m}^{2}$ ), the blasting rock volume is $510.3 \mathrm{~m}^{3}$, but the bulk rate reaches $0.373 \%$, which is $71.1 \%$ higher than $0.218 \%$ of $a \times W=8.5 \mathrm{~m} \times 5.5 \mathrm{~m}$, which corresponds to a worse blasting quality.

It can be seen that blasting quality of a rectangle is better than that of the square pattern. The rectangle of $a \times W=8.5 \mathrm{~m}$ $\times 5.5 \mathrm{~m}$ had a better blast quality with a large rock volume blasted. The advantages of large hole spacing with a small resistance line were proved.

\section{Conclusions}

(1) The volume of rock blasted and the blast quality are interassociated and mutually conflicting. To ensure good blasting quality and reduce the bulk yield, the charge depth or the resistant line should be reasonably reduced. This rational resistant line should be 0.86 times the reasonable resistant line (or the optimal charge depth).

(2) Uniform design was found to be an effective method for designing the program of blasting crater experiments that can reduce the number of tests, decrease the workload of blasting parameters optimization, and reduce the labor intensity. $\mathrm{R}^{2}$ of the regression equations for the volume of rock blasted and the bulk yield were 0.9881 and 0.9717, respectively. The two regression equations are reliable.

(3) The contribution rates of the resistance lines and the spacing of the holes to the blasting volume regression were $32.4 \%$ and $13.9 \%$, respectively, and to the bulk yield regression were $65.0 \%$ and $0.256 \%$, respectively. The effect of the resistance line on the volume of rock blasted and bulk rate is more significant than that of hole spacing. The amount of blasting is negatively related to the bulk yield.

(4) The blasting technology of large hole spacing and a small resistance line can reduce the bulk yield and improve blasting quality under the condition of ensuring a high blasting volume. The blasting effect of the rectangular blast hole arrangement is better than that of the square pattern. The economically reasonable blasting parameters are defined as a hole spacing of $8.5 \mathrm{~m}$ and a resistance line width of $5.5 \mathrm{~m}$, with a blasting volume of $413.1 \mathrm{~m}^{3}$ and bulk yield of $0.218 \%$. The bulk rate of a perfect square of $a \times W=6.843 \mathrm{~m} \times$ $6.837 \mathrm{~m}\left(46.75 \mathrm{~m}^{2}\right)$ in the same blasting area reached up to $0.373 \%$, which was $71.1 \%$ higher than that of an $8.5 \mathrm{~m} \times 5.5 \mathrm{~m}$ rectangle.

\section{Data Availability}

The data used to support the findings of this study are available from the corresponding author upon request.

\section{Conflicts of Interest}

The authors declare no conflicts of interest in preparing this article. 


\section{Acknowledgments}

This work was supported by the National Key R\&D Program of China (no. 2017YFC0602902), the National Natural Science Foundation of China (no. 51674229 and no. 51374189), and the Fundamental Research Funds for the Central Universities (no. WK2480000002). The authors acknowledge their financial support of this work.

\section{References}

[1] W. Xu-guang, Blasting Manual, Metallurgical Industry Press, Beijing, China, 2010.

[2] W. L. Fourney, R. D. Dick, X. J. Wang, and Y. Wei, "Fragmentation mechanism in crater blasting," in Proceedings of the International Journal of Rock Mechanics and Mining Sciences Geomechanics Abstracts, vol. 30, pp. 413-429, 1993.

[3] W. L. Fourney, R. D. Dick, and K. R. Y. Simha, "Model study of crater blasting," Rock Mechanics and Rock Engineering, vol. 21, no. 3, pp. 183-205, 1988.

[4] Z. LIU, Z. Chuan-qu, X. Dong-hai, C. Cai-xian, and H. Lei, "Optimized design and practice of blasting parameters for hard rock roadway with small cross-section," Journal of Mining \& Safety Engineering, vol. 24, no. 1, pp. 70-73, 2007 (Chinese).

[5] W. Yi-xian, Y. Yong-qiang, Y. Xiao-lin, and C. Huaibao, "Study on blasting parameters of coal based on blasting crater test," Blasting, vol. 27, no. 1, pp. 1-4, 2010 (Chinese).

[6] Y. Zhang and F. Xie, "Theoretical and test study on dynamicu characteristics of thin-layered sandy frozen soil in blasting," Journal of Computers, vol. 6, no. 6, pp. 1131-1138, 2011.

[7] Z. Zhe-ming, "Numerical prediction of crater blasting and bench blastisng," International Journal of Rock Mechanics \& Mining Sciences, vol. 46, no. 6, pp. 1088-1096, 2009.

[8] P. Yan, W. Zhou, W. Lu, M. Chen, and C. Zhou, "Simulation of bench blasting considering fragmentation size distribution," International Journal of Impact Engineering, vol. 90, pp. 132-145, 2016.

[9] S. H. Cho and K. Kaneko, "Influence of the applied pressure waveform on the dynamic fracture processes in rock," International Journal of Rock Mechanics and Mining Sciences, vol. 41, no. 5, pp. 771-784, 2004.

[10] X. H. Jin, "Discussion on blasting crater theory," Rock \& Soil Mechanics, vol. 33, pp. 205-208, 2002 (Chinese).

[11] W. Ming-zheng, S. Xiu-zhi, Z. Jian, and Q. Xian-yang, "Multiplanar detection optimization algorithm for the interval charging structure of large-diameter longhole blasting design based on rock fragmentation aspects," Engineering Optimization, vol. 5, pp. 1-15, 2018.

[12] M. Yamamoto, H. Noda, and K. Kaneko, "Experimental study on blast vibration control method, which is based upon wave interference," Smart Structures \& Systems, vol. 59, no. 1, pp. 119137, 1998.

[13] S. K. Mandal, "Mathematical model to locate interference of blast waves from multi-hole blasting rounds," Engineering, vol. 4, no. 3, pp. 146-154, 2012.

[14] D. Baratoux and H. J. Melosh, "The formation of shatter cones by shock wave interference during impacting," Earth and Planetary Science Letters, vol. 216, no. 1-2, pp. 43-54, 2003.

[15] F. Kai-Tai, K. J. L. Dennis, P. Winker, and Y. Zhang, "Uniform design: theory and application," Technometrics, vol. 42, no. 3, pp. 237-248, 2000.
[16] Y.-Z. Liang, F. Kai-Tai, and Q.-S. Xu, "Uniform design and its applications in chemistry and chemical engineering," Chemometrics Intelligent Laboratory Systems, vol. 58, no. 1, pp. 43-57, 2001.

[17] F. Kai-Tai, "The uniform design: Application of number-theoretic methods in experimental design," Acta Mathematicae Applicatae Sinica, vol. 3, no. 4, p. 9, 1980.

[18] C.-M. Huang, Y.-J. Lee, D. K. J. Lin, and S-Y. Huang, "Model selection for support vector machines via uniform design," Computational Statistics \& Data Analysis, vol. 52, no. 1, pp. 335346, 2007.

[19] J.-P. Wang, Y.-Z. Chen, Y. Wang, S.-J. Yuan, and H.-Q. Yu, "Optimization of the coagulation-flocculation process for pulp mill wastewater treatment using a combination of uniform design and response surface methodology," Water Research, vol. 45, no. 17, pp. 5633-5640, 2011.

[20] Y. Kuo, T. Yang, B. A. Peters, and I. Chang, "Simulation metamodel development using uniform design and neural networks for automated material handling systems in semiconductor wafer fabrication," Simulation Modelling Practice and Theory, vol. 15, no. 8, pp. 1002-1015, 2007. 


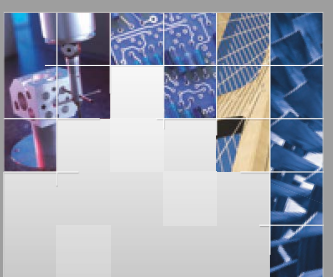

\section{Enfincering}
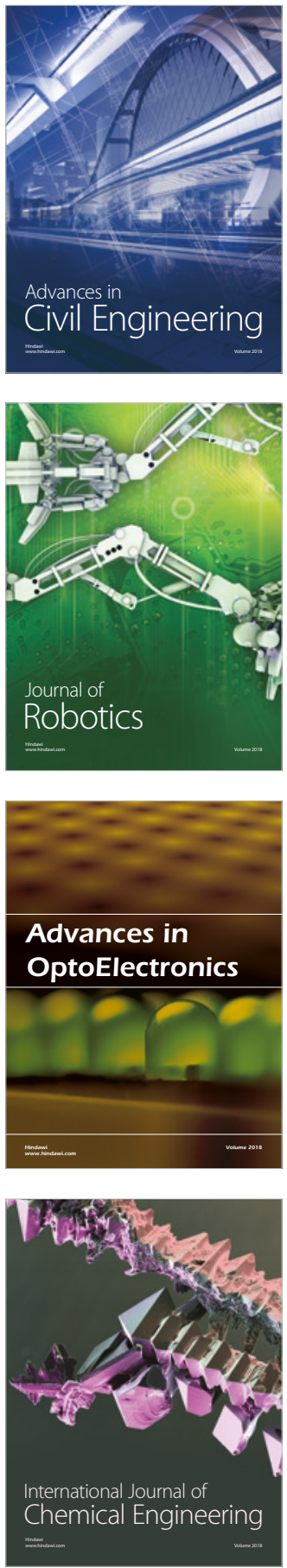

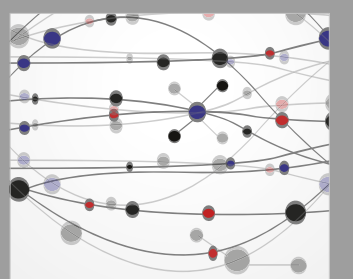

\section{Rotating \\ Machinery}

The Scientific World Journal

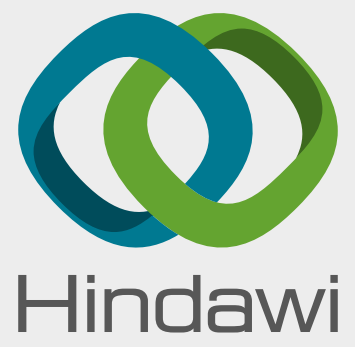

Submit your manuscripts at

www.hindawi.com
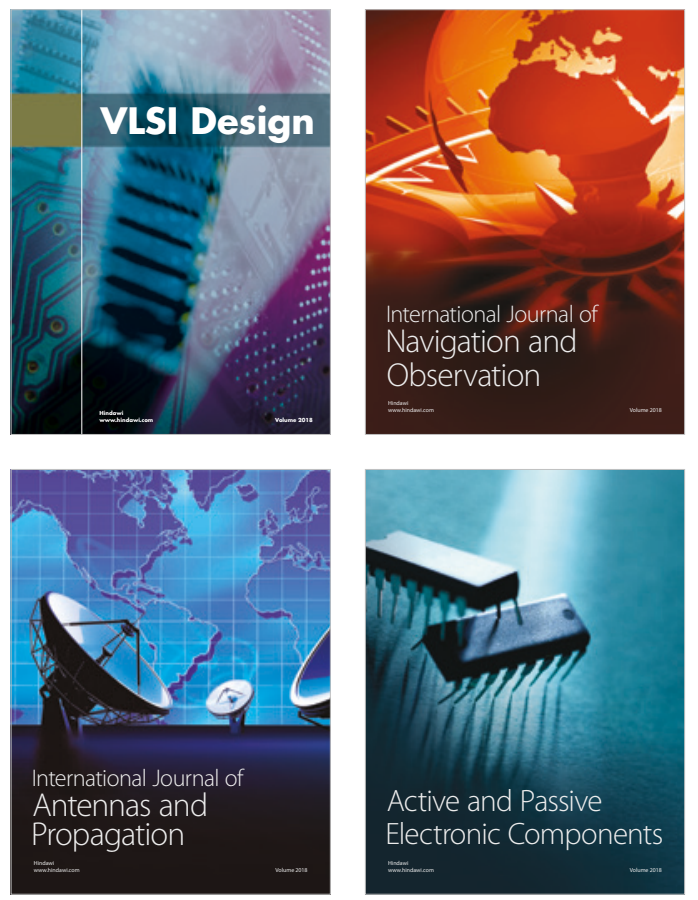
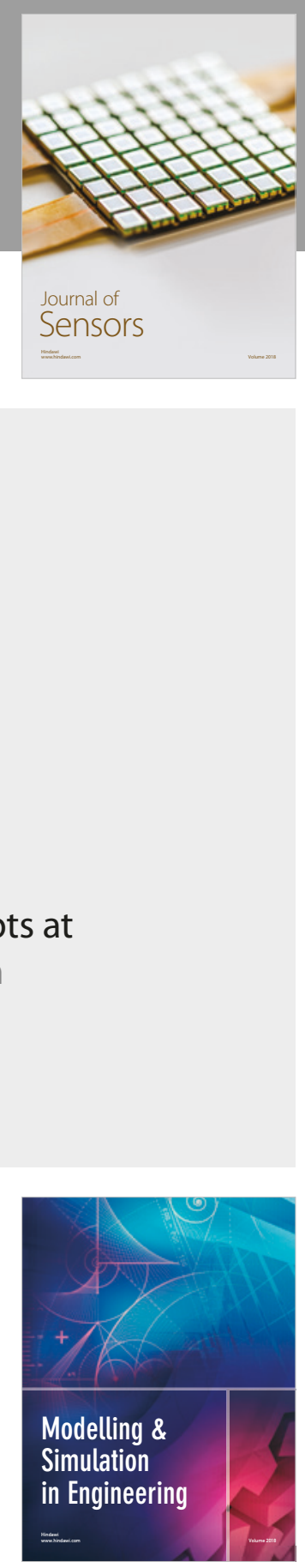

\section{Advances \\ Multimedia}
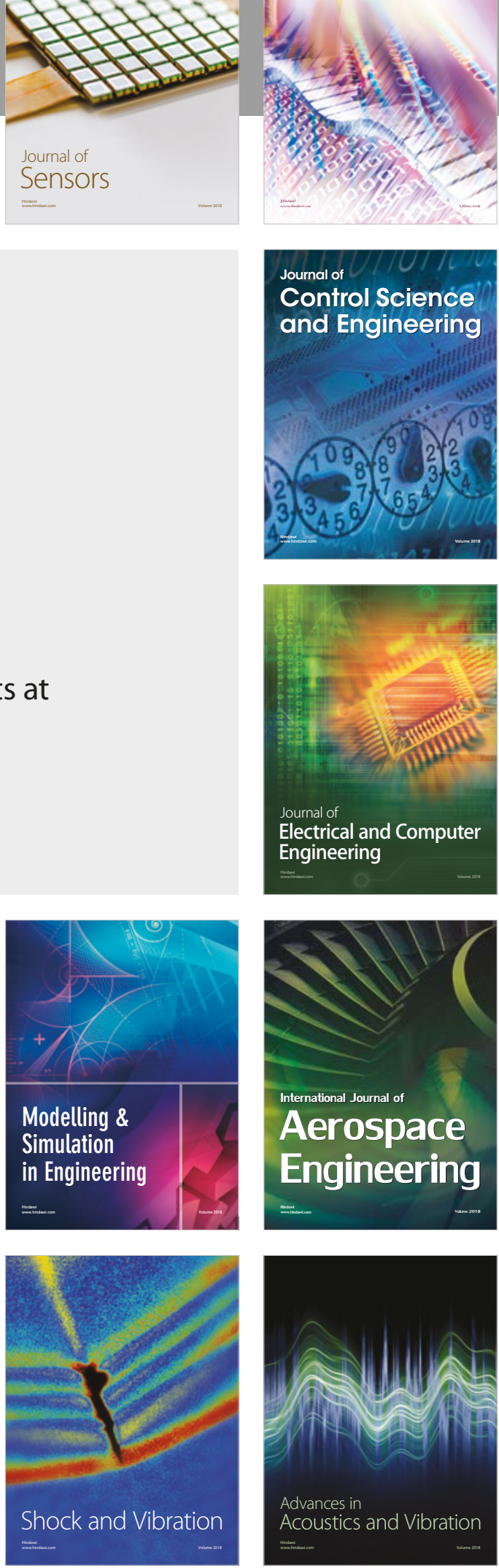